\title{
SITUAÇÃO ATUAL DA MATA CILIAR DO RIBEIRÃO SÃO BARTOLOMEU EM VIÇOSA, MG ${ }^{1}$
}

\author{
Daniel Assumpção Costa Ferreira ${ }^{2}$, Herly Carlos Teixeira Dias ${ }^{3}$
}

\begin{abstract}
RESUMO - O presente trabalho teve como objetivos fazer o levantamento de remanescentes de mata ciliar existentes ao longo de um trecho do curso principal do ribeirão São Bartolomeu, em Viçosa, MG, e estimar a área a ser revegetada com espécies nativas da região, através de uma metodologia simples, porém eficaz no caso de pequenos cursos de água e com pouca área de preservação permanente com floresta. A área em estudo apresentou apenas 5,7\% da área de mata ciliar que deveria existir de acordo com a legislação vigente, representada por nove fragmentos florestais em diferentes estágios de sucessão ecológica, totalizando 3,46 ha. Para a revegetação completa do trecho em estudo, propôs-se um modelo de plantio baseado na combinação de espécies de diferentes grupos ecológicos. A área a ser revegetada para atender às exigências da legislação é de 57,24 ha, e serão necessárias cerca de 82.830 mudas de espécies nativas da região para o plantio.
\end{abstract}

Palavras-chave: Mata ciliar, recursos hídricos, hidrologia, ribeirão São Bartolomeu.

\section{PRESENT SITUATION OF RIPARIAN FOREST ALONG RIBEIRÃO SÃO BARTOLOMEU, VIÇOSA, MG}

\begin{abstract}
This study surveyed the present riparian forest along a segment of the São Bartolomeu watershed, Viçosa, MG, and estimated the area that should be planted with native species, using a simple and effective method for measuring small drainage systems. The segment studied showed that only $5.7 \%$ of the legally required riparian forest exists, represented by nine forest fragments in different stages of ecological succession for a total area of 3.46 hectares. In order to revegetate completely the riparian study area, a model plantation based on a species combination of different ecological groups is proposed. The area to be revegetated in order to obey current legislation is 57.24 hectares, meaning that about 82,830 seedlings of native species will need to be planted.
\end{abstract}

Key words: Riparian forest, watershed hydrology, rain forest zone.

Nunca, em toda a história da humanidade, a utilização dos recursos naturais pelo ser humano foi tão questionada. Tanto no meio científico quanto entre a população em geral, é crescente a idéia de conservação dos ecossistemas naturais e de recuperação dos ecossistemas degradados pelo homem.

As florestas nativas, representadas por diferentes biomas, são importantes ecossistemas que há séculos são explorados de forma degradatória.

Esse processo de eliminação das florestas resultou num conjunto de problemas ambientais, como a extinção de várias espécies da fauna e flora, mudanças climáticas locais, erosão dos solos, eutrofização e assoreamento dos cursos d'água.

Nesse panorama, as matas ciliares não escaparam da destruição e foram alvo de todo tipo de de-

\footnotetext{
${ }^{1}$ Recebido para publicação em 17.5.2003 e aceito para publicação em 10.8.2004.

${ }^{2}$ Instituto Nacional de Pesquisas da Amazônia, INPA, Manaus. E.mail:<danielassumpcao@ yahoo.com.br>.

${ }^{3}$ Departamento de Engenharia Florestal da UFV. E.mail: <herly@ ufv.br>.
} 
gradação. Basta considerar que muitas cidades foram formadas às margens dos rios, eliminando todo tipo de vegetação ciliar, e muitas sofrem hoje com constantes inundações, poluição, doenças e modificação da paisagem, efeitos negativos desses atos depredatórios.

De acordo com Martins (2001), além do processo de urbanização, as matas ciliares sofrem pressão antrópica também por uma série de fatores. São áreas diretamente afetadas por construção de hidrelétricas, abertura de estradas em regiões com topografia acidentada e implantação de culturas agrícolas e de pastagem.

A intervenção humana em área de mata ciliar, além de ser proibida pela legislação federal, causa uma série de danos ambientais. As matas ciliares atuam como barreira física, regulando os processos de troca entre os ecossistemas terrestres e aquáticos e desenvolvendo condições propícias à infiltração (KAGEYAMA,1986; LIMA, 1989). Sua presença reduz significativamente a possibilidade de contaminação dos cursos d'água por sedimentos, resíduos de adubos e defensivos agrícolas, conduzidos pelo escoamento superficial da água no terreno.

Segundo Lourence et al. (1984), citados por Ribeiro (1998), o ecossistema mata ciliar comporta-se como excelente consumidor e tampão de nutrientes que estão presentes no escoamento advindo de agrossistemas vizinhos.

O ribeirão São Bartolomeu é o responsável por parte do abastecimento de água da cidade de Viçosa, que hoje conta com uma população de aproximadamente 64.000 habitantes. Para suprir a necessidade diária de água da população da cidade durante os meses de seca, o Serviço Autônomo de Água e Esgoto (SAAE) faz a captação também em outra bacia hidrográfica. Parte da água utilizada pela Universidade Federal de Viçosa também é extraída desse ribeirão.

O aumento da população e o conseqüente incremento da demanda de água reforçam a idéia de que medidas de recuperação e conservação da bacia são extremamente necessárias para que o ribeirão consiga suprir essa demanda, e a implantação de um plano de manejo da bacia é indispensável ao atendimento desta. A conservação e recuperação das matas ciliares e o manejo sustentável de bacias hidrográficas

R. Árvore, Viçosa-MG, v.28, n.4, p.617-623, 2004 afetam diretamente a qualidade e a quantidade de água, a manutenção do microclima da região e a preservação da fauna silvestre e aquática, entre outros.

Sabendo-se da importância da conservação e recuperação das matas ciliares para a manutenção e melhoria da qualidade de vida do homem e dos ecossistemas em que vive, este trabalho teve como objetivos:

a) Levantar os remanescentes de mata ciliar do ribeirão São Bartolomeu situado no município de Viçosa, MG, na região da Zona da Mata.

b) Estimar a área a ser revegetada com espécies nativas da região, com base nas exigências da legislação federal em vigor.

Para o levantamento dos fragmentos de mata ciliar, aqui denominados Área de Mata Ciliar Atual, considerou-se apenas a extensão do ribeirão São Bartolomeu a montante da cidade de Viçosa (Figura 1), ou seja, da sua nascente até o ponto que cruza a rodovia MG-280, no bairro Rua Nova, no campus da UFV. A nascente considerada no caso foi aquela localizada na comunidade Palmital, já que é a nascente mais distante da foz.

Para orientação do trabalho e medição do comprimento do ribeirão, utilizou-se como base a FOLHA VIÇOSA, IBGE, 1:50000, 1979 (SF-23-X-B-V-3).

Para o levantamento da Área de Mata Ciliar Atual (AMcA), percorreu-se toda a extensão do ribeirão. Os fragmentos encontrados até $30 \mathrm{~m}$ de distância das margens desse percurso foram contornados e tiveram seus pontos registrados como polígonos delimitados pelas coordenadas geográficas coletadas pelo Global Position System (GPS), da marca Garmin II Plus, e considerados no domínio do ecossistema fluvial.

Os pontos foram transferidos para a memória do computador, calculando-se, através do software Excel, a área de cada fragmento encontrado, cujo total foi determinado a partir da soma das áreas desses remanescentes.

A Lei n ${ }^{\circ}$ 4.771, de 15/09/65 - Código Florestal, em seus artigos $1^{\circ}, 2^{\circ}$ e $3^{\circ}$, trata das florestas e demais formas de vegetação de preservação permanente. Determina que todo rio com largura de até $10 \mathrm{~m}$, como é o caso do ribeirão São Bartolomeu, deve possuir faixa de $30 \mathrm{~m}$, no mínimo, de mata ciliar acompanhan- 
do cada uma de suas margens, dentro da área de preservação permanente. Essa faixa é aqui denominada Área de Mata Ciliar Legal (AMcL).

Para o cálculo da AMcL, multiplicou-se o comprimento do trecho do ribeirão em estudo, que foi determinado utilizando software ArcView GIS 3.2 sobre a imagem da rede de drenagem da Bacia do São Bartolomeu, pela largura da área de preservação permanente, aqui chamada de faixa legal.

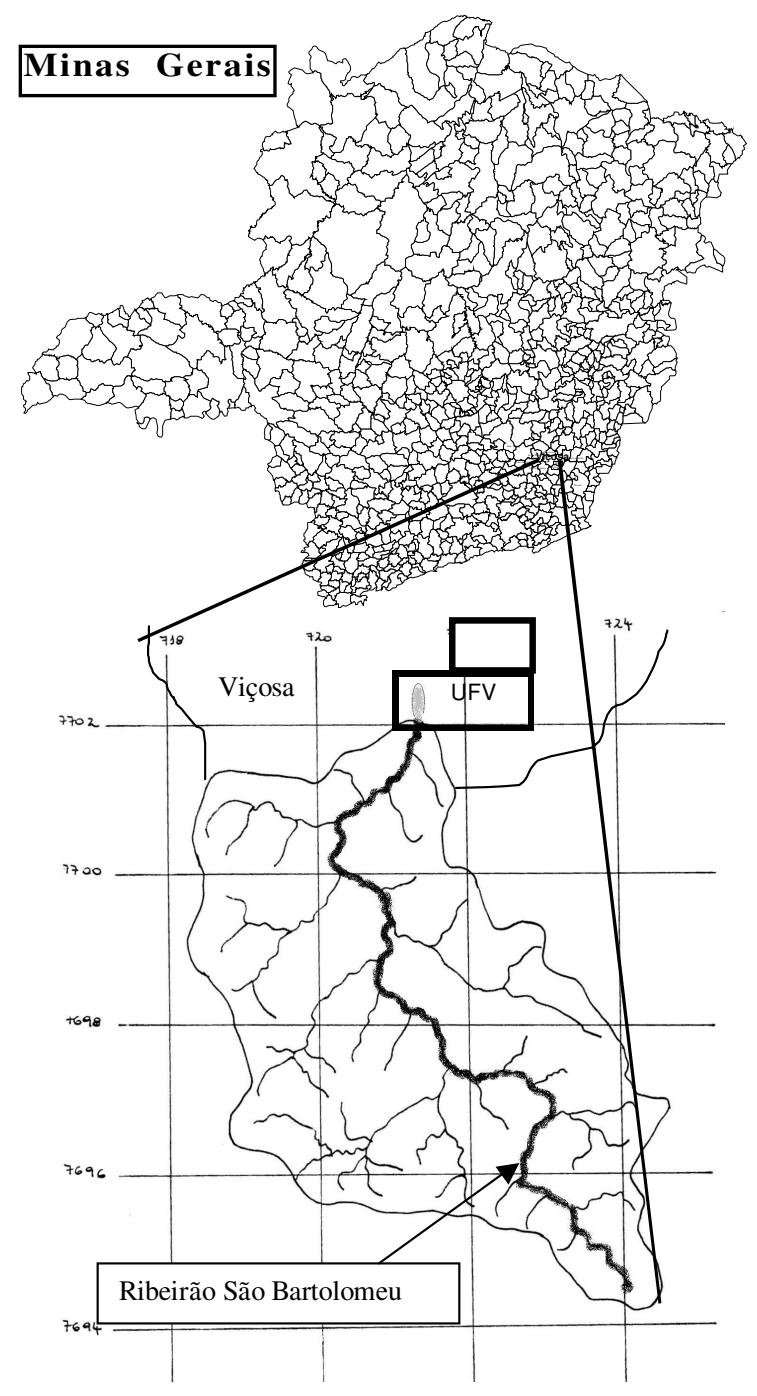

Figura 1 - Bacia do ribeirão São Bartolomeu, Viçosa - MG. Figure 1 - Watershed of the River São Bartolomeu, Viçosa, $M G$.
$\mathrm{AMcL}=$ Comprimento do Rio $\mathrm{x}$ Largura da Faixa Legal

A área ao longo do ribeirão que deve ser revegetada está sendo aqui denominada Área de Mata Ciliar a ser Recuperada (AMcR). Para obter AMcR, subtraiuse AMcA de AMcL.

$$
\mathrm{AMcR}=\mathrm{AMcL}-\mathrm{AMcA}
$$

Essa estimativa permite, então, determinar a área e o número de mudas de espécies arbóreas a serem empregadas no processo de revegetação, de acordo com o espaçamento entre as mudas e a área do terreno.

Ao longo do trecho do ribeirão São Bartolomeu em estudo, foram encontrados nove fragmentos de mata ciliar (Tabela 1) em diferentes estádios de sucessão ecológica, ou seja, todos os fragmentos já havia sofrido algum tipo de ação antrópica. A existência de apenas 3,4 ha com mata ciliar demonstra a pouca importância que se dá as estas áreas na região. Verificou-se que uma prática muito comum é a exploração desses fragmentos em busca de madeira para usos domésticos, como lenha, carvão, mourão de cerca e cabo de ferramenta. Campos e Langraf (2001) ressaltaram, inclusive, que muitas espécies florestais destes ambientes se encontram em via de extinção principalmente em conseqüência do seu valor econômico e do sistema seletivo de exploração.

Tabela 1 - Fragmentos de mata ciliar encontrados às margens do ribeirão São Bartolomeu, a montante da cidade de Viçosa, em março de 2002

Table 1 - Area of the nine riparian forest fragments found in São Bartolomeu riverbanks, upstream Viçosa, MG, march 2002

\begin{tabular}{cc}
\hline FRAGMENTO DE & ÁREADE \\
MATA CILIAR & MATA CILIAR (ha) \\
\hline 1 & 0,1763 \\
2 & 0,9811 \\
3 & 0,0826 \\
4 & 0,7191 \\
5 & 0,3722 \\
6 & 0,1707 \\
7 & 0,3437 \\
8 & 0,4608 \\
9 & 0,1578 \\
TOTAL & 3,4649 \\
\hline
\end{tabular}

R. Árvore, Viçosa-MG, v.28, n.4, p.617-623, 2004 
Em muitas propriedades que se estendiam até a margem do ribeirão, a mata ciliar foi suprimida para dar lugar a pomares, em especial para o plantio de bananas, conforme a constatação no percurso visitado. Em geral, as margens dos rios são os terrenos mais férteis de uma propriedade, portanto são as primeiras áreas utilizadas para a prática agrícola.

A ocorrência de bambuzais nas margens do ribeirão era também bastante freqüente. Estes não foram contabilizados como fragmentos de mata ciliar, pois, embora ocorram bem às margens do ribeirão, o bambu não possui a diversidade florística nem a importância ecológica necessária para-se classifica-lo como tal.

O comprimento do curso d'água principal encontrado pela metodologia proposta foi de $10118,591 \mathrm{~m}$. A área a ser respeitada nesse percurso é de $30 \mathrm{~m}$ para cada margem do ribeirao, ou seja, $60 \mathrm{~m}$ no total. Assim, a área de mata ciliar do curso principal é equivalante a 60,711 ha. Embora ainda criticada por muitos, resultados demonstram a importância dessa faixa de proteção dos cursos d'água. De acordo com o que foi obtido por Lima e Leopoldo (1999), por exemplo, a mata ciliar desenvolveu relevante papel no comportamento do ciclo hidrológico estudado.

Sabendo que a área de mata ciliar legal é de 60,711 ha e que a fração existente é de 3,4649 ha, observouse que existe uma área a ser reflorestada, para atender às exigências da legislação, equivalente a 57,2461 ha.

É valido ressaltar que a coerência dessa largura da faixa de mata ciliar, determinada pela legislação, não é objeto de discussão deste trabalho, no entanto atualmente existe uma preocupação maior com esse assunto, e dessa forma estudos, como aquele apresentado por Simões (2001), apontam que essa faixa de mata ciliar deve ser determinada de acordo com as características morfológicas da bacia, como a declividade e comprimento de rampa do terreno, com a classe de solo predominante e suas características físicoquímicas, entre outras.

Diante das condições observadas, surge a grande preocupação sobre qual processo poderia ser implementado para a revegetação da área de preservação permanente referida.

Certamente, a recuperação da mata ciliar é importante, entre outras razões, para o armazenamento de água de chuva. De acordo com Lima (1998), o armazenamento temporário de água de chuva pelo ecossistema estudado foi bastante significativo, representando, em média, 93,4\% da precipitação total.

Devido ao grande número de variáveis ambientais que podem interferir no comportamento das espécies em determinado sítio (MARTINS, 2001), a escolha de um modelo adequado é essencial para o sucesso da recuperação da área de mata ciliar. De acordo com Alvarenga (2004), dos vários métodos de regeneração existentes, devem-se observar vários critérios para escolha do melhor em cada situação. De fato, além dos critérios silviculturais, os critérios econômicos, custo da operação, e paisagísticos devem ser considerados.

No caso do ribeirão São Bartolomeu, que se encontra em estágio avançado de degradação, caso seja iniciado um processo de reflorestamento da zona ripária sugere-se um modelo sucessional que se baseie na combinação de espécies de diferentes grupos ecológicos ou categorias sucessionais. Parte-se do princípio de que espécies de início de sucessão, intolerantes à sombra e de crescimento rápido, devem fornecer condições ecológicas, principalmente sombreamento, favoráveis ao desenvolvimento de espécies finais de sucessão, ou seja, aquelas que necessitam de sombra, pelo menos na fase inicial do crescimento.

De acordo com IEF (1994), a maneira mais prática de dispor as mudas no campo é alternando uma linha de espécies pioneiras com outra de espécies secundárias e clímax, conforme o desenho a seguir:

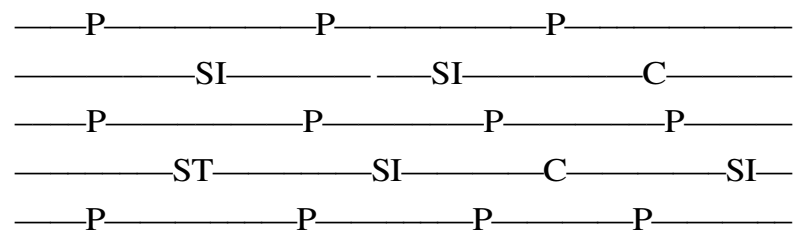

Em que:

$\mathrm{P}=$ espécie pioneira; $\mathrm{SI}=$ espécie secundária inicial;

$\mathrm{ST}=$ espécie secundária tardia e $\mathrm{C}=$ espécie clímax.

Um espaçamento sugerido por diversos pesquisadores, para as covas de plantio, é de três metros entre plantas e de três metros entre linhas, com as espécies 
clímax no centro, distribuindo-se as pioneiras e as secundárias nas laterais. Da mesma forma, recomendam-se que as mudas destinadas ao plantio sigam a seguinte proporção: $50 \%$ de pioneiras, $30 \%$ de secundárias iniciais, $10 \%$ de secundárias tardias e $10 \%$ de espécies clímax. Assim, para cada ha implantado serão necessárias 1.113 mudas, e para a área a ser recuperada, considerando-se uma margem de $30 \%$ de replantio, serão necessárias 82.830 mudas, que, de acordo com a proporção sugerida, poderão ser assim distribuídas:

$$
\begin{array}{lll}
50 \% \text { de pioneiras } & -41.415 \text { mudas } \\
30 \% \text { de secundárias iniciais } & -24.849 \text { mudas } \\
10 \% \text { de secundárias tardias } & -8.283 \text { mudas } \\
10 \% \text { de clímax } & -8.283 \text { mudas }
\end{array}
$$

Ao adotar-se o modelo de recuperação que utilize maior número de espécies, combinando os diferentes grupos sucessionais, maior será o suporte para a restauração da função ecológica da mata ciliar e de sua sustentabilidade. Napo et al. (1999) ressaltaram ainda que a indução da dinâmica de sucessão secundária, mediante intervenções de plantio, tem apresentado resultados muito favoráveis quanto à recuperação da função e à posterior recuperação da estrutura da floresta.

De acordo com Durigan e Nogueira (1990), as espécies a serem plantadas em cada local devem ser aquelas que ocorrem naturalmente em condições de clima, solo e umidade semelhantes às da área a reflorestar. Assim, a escolha de espécies com base em levantamentos florísticos e fitossociológicos de remanescentes da região e a posterior combinação com grupos de sucessão constituem o procedimento mais indicado para o recomposição de matas ciliares.

Conforme sugestão de IEF (1994), Martins (2001), Durigan e Nogueira (1990), Nappo (1999), na Tabela 2 encontram-se algumas espécies com potencial para a reconstituição de matas ciliares.

De acordo com os resultados deste trabalho, ficou evidente o grave estado de degradação ambiental em que se encontra a área de preservação permanente do ribeirão São Bartolomeu. Da área de mata ciliar que deveria existir, segundo a legislação em vigor, só restam $5,7 \%$, comprometendo o conceito de "desenvolvimento sustentável" para a região.

Tabela 2 - Sugestão de espécies arbustivo-arbóreas com potencial para recuperação da mata ciliar de acordo com a revisão

\begin{tabular}{|c|c|c|c|c|}
\hline Nome comum & Nome científico & G. E & $\mathrm{N}^{\mathrm{o}}$ de mudas & S. A \\
\hline$\overline{\text { Casca-doce }}$ & Alchornea iricurana Casar. & $\overline{\mathrm{P}}$ & 1883 & $\mathrm{~A}$ \\
\hline Belém & Alchornea triplinervia (Spring.) Mull. Arg. & $\mathrm{P}$ & & B \\
\hline Três folhas vermelhas & Allophylus edulis (A. st. - Hil.) Radek. & $\mathrm{P}$ & & B-C \\
\hline Unha de vaca & Bauhinia sp & $\mathrm{P}$ & & B \\
\hline Café do Mato & Casearia sylvestres $\mathrm{SW}$. & $\mathrm{P}$ & & $\mathrm{C}$ \\
\hline Embauba formiga & Cecropia adenopus Mart. ex Mig. & $\mathrm{P}$ & & A-B \\
\hline Embauba branca & Cecropia hololeuca Mig. & $\mathrm{P}$ & & B-C \\
\hline Capixingui & Croton floribundus Spreng. & $\mathrm{P}$ & & $\mathrm{C}$ \\
\hline Adrago & Croton urucurana Baill. & $\mathrm{P}$ & & A-B \\
\hline Brauninha & Dyctioloma incanecens DC. & $\mathrm{P}$ & & B-C \\
\hline Caroba & Jacaranda $\mathrm{sp}$ & $\mathrm{P}$ & & $\mathrm{C}$ \\
\hline Açoita cavalo & Luehea speciosa Willd. & $\mathrm{P}$ & & B-C \\
\hline Canudo de pito & Mabea fistulifera Mart. & $\mathrm{P}$ & & $\mathrm{C}$ \\
\hline Jambo branco & Mapronea guianensis Aubl. & $\mathrm{P}$ & & $\mathrm{C}$ \\
\hline Jambo vermelho & Myrcia sp & $\mathrm{P}$ & & B-C \\
\hline Pessegueiro do mato & Prunus sellowii Kochne & $\underline{P}$ & & $\mathrm{C}$ \\
\hline
\end{tabular}
bibliográfica. $\mathrm{GE}=$ grupo ecológico: $\mathrm{P}=$ pioneira, $\mathrm{C}=$ clímax, $\mathrm{S}=$ secundária, $\mathrm{SA}=$ saturação de água no solo: $\mathrm{A}=$ terrenos alagadiços ou brejosos, $\mathrm{B}=$ terrenos inundados periodicamente e $\mathrm{C}=$ terrenos bem drenados

Table 2 -Suggestion of shrub-tree species for riparian forest recovery. $G E=$ ecological group: $P=$ pioneer, $C=c l i m a x$, $S=$ secondary, $S A=$ water saturation in the soil: $A=$ terrestrial swamps, $B=$ lands periodically flooded, $C=$ well drained lands 
Quadro 2, cont.

Table 2, cont..

\begin{tabular}{|c|c|c|c|c|}
\hline Nome Comum & Nome científico & G. E & $\mathrm{N}^{\circ}$ de mudas & S.A \\
\hline Imbiriçu & Pseudobombax sp & $\mathrm{P}$ & & A-B \\
\hline Goiabeira & Psidium guajava $\mathrm{L}$. & $\mathrm{P}$ & & $\mathrm{B}-\mathrm{C}$ \\
\hline Ipê mulato & Tabebuia chrysotricha (Mart. ex DC.) Standl. & $\mathrm{P}$ & & $\mathrm{C}$ \\
\hline Osso-de-frango & Terminalia sp & $\mathrm{P}$ & & $\mathrm{C}$ \\
\hline Pau-de-fumo & Vernonia diffusa Less. & $\mathrm{P}$ & & A \\
\hline Pindaiba & Xylopia sericea A. St. - Hil. & $\mathrm{P}$ & & $\mathrm{C}$ \\
\hline Adrago & Croton urucurana & $\mathrm{S}$ & 1657 & A-B \\
\hline Camboatá-preto & Cupania vernalis Lambess. & $\mathrm{S}$ & & $\mathrm{C}$ \\
\hline Sessenta e um & Erythroxylum sp & $\mathrm{S}$ & & A \\
\hline Liquerana & Hyeronima alalchorneoides Allemão & $\mathrm{S}$ & & A-B \\
\hline Ingá & Inga sp & S & & A-B \\
\hline Açoita cavalo & Luehea speciosa & $\mathrm{S}$ & & $\mathrm{B}-\mathrm{C}$ \\
\hline Bico-de-pato & Machaerium nyctitans (Vell.) Benth. & $\mathrm{S}$ & & $\mathrm{B}-\mathrm{C}$ \\
\hline Feijão cru & Machaerium stipitatum (DC.) Vogel. & $\mathrm{S}$ & & $\mathrm{B}-\mathrm{C}$ \\
\hline Camboatá vermelho & Matayba elaeagnoides Radek. & $\mathrm{S}$ & & $\mathrm{B}-\mathrm{C}$ \\
\hline Jacaré & Piptadenia gonoacantha (Mart.) J.F. Macbr. & $\mathrm{S}$ & & $\mathrm{C}$ \\
\hline Canela azeitona & Myrsine ferruginea (SW.) R.Br. ex Roem. \& Schult. & $\mathrm{S}$ & & $\mathrm{C}$ \\
\hline Araticum & Rollinia sp & $\mathrm{S}$ & & B \\
\hline Mamoneira branca & Sclerolobium sp & $\mathrm{S}$ & & $\mathrm{C}$ \\
\hline Fedegoso & Senna macranthera (Collad.) Irwin \& Barn. & $\mathrm{S}$ & & $\mathrm{C}$ \\
\hline Ipê preto & Zeyhera tuberculosa (Vell.) Bureau & $\mathrm{S}$ & & $\mathrm{C}$ \\
\hline Vaquinha branca & Annona sp & $\mathrm{C}$ & 1105 & B \\
\hline Garapa & Apuleia leiocarpa (Vogel) J.F. Macbr. & $\mathrm{C}$ & & $\mathrm{C}$ \\
\hline Peroba & Aspidosperma ramiflorum Mull. Arg. & $\mathrm{C}$ & & $\mathrm{B}-\mathrm{C}$ \\
\hline Cangerana & Cabralea canjerana (Vell.) Mart. subsp. Cangerana & $\mathrm{C}$ & & $\mathrm{B}-\mathrm{C}$ \\
\hline Jequitibá rosa & Cariniana estrelensis (Raddi) Kuntze. & $\mathrm{C}$ & & $\mathrm{C}$ \\
\hline Copaiba & Copaífera langsdorff Desf. & $\mathrm{C}$ & & $\mathrm{C}$ \\
\hline Jacarandá caviúna & Dalbergia nigra (Vell.) Allemão ex Benth. & $\mathrm{C}$ & & $\mathrm{C}$ \\
\hline Morotó & Schefflera morotoni (Aubl.) Decne. \& Planch. & $\mathrm{C}$ & & $\mathrm{C}$ \\
\hline Cura madre & Guarea guidonia (L.) Sleumer & $\mathrm{C}$ & & A-B \\
\hline Canela amarela & Nectranda rigida (H.B.K.) Nees. & $\mathrm{C}$ & & $\mathrm{B}-\mathrm{C}$ \\
\hline Canela coquinho & Nectranda saligna Nees \& Mart. & $\mathrm{C}$ & & $\mathrm{B}-\mathrm{C}$ \\
\hline Canela sassafrás & Ocotea pretiosa (Nees) Mez & $\mathrm{C}$ & & $\mathrm{C}$ \\
\hline Angico vermelho & Piptadenia peregrina (L.) Speg. & $\mathrm{C}$ & & $\mathrm{C}$ \\
\hline Bacupari & Rheedia brasiliensis Planch. \& Triana & $\mathrm{C}$ & & $\mathrm{B}-\mathrm{C}$ \\
\hline Bicuiba & Virola ocifera (Schott) A.C. Sm. & $\mathrm{C}$ & & $\mathrm{B}-\mathrm{C}$ \\
\hline
\end{tabular}

Para a recomposição completa de sua mata ciliar, estima-se que serão necessárias total de 82.830 mudas de espécies nativas da região, a fim de revegetar uma área total de 57,24 ha. Embora seja, em curto prazo, um processo oneroso, é de extrema importância para a manutenção da qualidade de vida da população e imprescindível ao desenvolvimento sustentável do município.

Embora simples, a metodologia utilizada mostrouse eficaz para um pequeno curso d'água e com pouca área de preservação permanente protegida, como na situação estudada.

R. Árvore, Viçosa-MG, v.28, n.4, p.617-623, 2004
Cabe ainda salientar que esta medida por si só não resolverá todos os problemas referentes a recursos hídricos da região. É preciso que se elabore um plano de manejo que contemple toda a Bacia do Ribeirão São Bartolomeu, tanto nos meios físicos e bióticos quanto, principalmente, no meio sócioeconômico.

\section{REFERÊNCIAS BIBLIOGRÁFICAS}

AlVArenga, A. P. Avaliação incial da recuperação de mata ciliar em nascentes. 2004. 175f. Dissertação (Mestrado em Engenharia Florestal), Universidade Federal de Lavras, Lavras, 2004. 
CAMPOS, J.C.; LANDGRAF, P.R.C. Análise da regeneração natural de espécies florestais em matas ciliares de acordo com a distância da margem do lago. Ciência Florestal, v. 11, n. 2, p.143-151, 2001.

DURIGAN, G.; NOGUEIRA, J. C. B.

Recomposição de matas ciliares:

orientações básicas. São Paulo: IF, n. 4, 14 p. 1990. (Série Registros)

INSTITUTO ESTADUAL DE FLORESTAS - IEF. Matas ciliares: proteção de solo e água. Belo Horizonte: 1994 b, 18p.

KAGEYAMA.P.Y. Estudo para implantação de matas de galeria na bacia hidrográfica do Passa Cinco visando a utilização para abastecimento público. Piracicaba: Universidade de São Paulo, 1986. 236p. Relatório de Pesquisa.

LIMA, W.P. Função hidrológica da mata ciliar. In: SIMPÓSIO SOBRE MATA CILIAR, 1., 1989,

Campinas. Anais... Campinas: Fundação Cargil, 1989. p 25-42.

LIMA, P.R.A. Retenção de água de chuva por mata ciliar na região central do estado de São Paulo. 1998. 99f, Dissertação (Mestrado em Agronomia - Energia na Agricultura) - Universidade Estadual de Paulista, 1998.
LIMA, P.R.A.; LEPOLDO, P.R. Interceptação de chuva por mata ciliar na região central do estado de São Paulo. Energia na Agricultura, v. 14, n.3, p.25-33, 1999.

MARTINS, S. V. Recuperação de Matas

Ciliares. Viçosa, MG: Aprenda Fácil, 2001. 143p.

NAPPO, M. E., GOMES, L. J.; CHAVES, M. M. F. Reflorestamentos mistos com essências nativas para recomposição de matas ciliares. Boletim Agropecuário da Universidade Federal de Lavras, v.30, p.1 - 31, 1999

RIBEIRO, J. F. Cerrado: matas de galeria. Planaltina: EMBRAPA-CPAC, 1998. 164p.

SIMÕES, L.B. Integração entre um modelo de simulação hidrológica e sistema de informação geográfica na delimitação de zonas tampão ripárias. 2001, 183f. Tese (Doutorado em Agronomia)Universidade Estadual Paulista, Botucatu, 2001. 